\title{
External cavity setup for beam quality improvement of a broad-stripe segmented diode
} laser

Thestrup, B.; Petersen, P.M.

Publication date:

2005

Document Version

Publisher's PDF, also known as Version of record

Link back to DTU Orbit

\section{Citation (APA):}

Thestrup, B., \& Petersen, P. M. (2005). External cavity setup for beam quality improvement of a broad-stripe segmented diode laser. Abstract from European Conference on Lasers and Electro-Optics - European Quantum Electronics Conference 2005, Munich, Germany.

\section{General rights}

Copyright and moral rights for the publications made accessible in the public portal are retained by the authors and/or other copyright owners and it is a condition of accessing publications that users recognise and abide by the legal requirements associated with these rights.

- Users may download and print one copy of any publication from the public portal for the purpose of private study or research.

- You may not further distribute the material or use it for any profit-making activity or commercial gain

- You may freely distribute the URL identifying the publication in the public portal

If you believe that this document breaches copyright please contact us providing details, and we will remove access to the work immediately and investigate your claim 


\title{
External cavity setup for beam quality improvement of a broad-stripe segmented diode laser
}

Birgitte Thestrup and Paul Michael Petersen, Optics and Plasma Research Department, Risø National Laboratory, Frederiksborgvej 399, 4000 Roskilde, Denmark.

\begin{abstract}
We demonstrate a new setup for selective off-axis feedback of a broad-stripe segmented diode laser leading to significant improvement of the overall spatial coherence of the output beam. Results with a 5 segmented diode are presented.
\end{abstract}

\section{Introduction}

Segmented diode lasers and diode laser bars are attractive due to their compactness and simplicity of operation. However, these devices suffer from poor spatial coherence along the slow axis, and this prohibits coupling of the laser beams into, e.g., thin core fibres. The spatial coherence properties of broad single emitters can be improved significantly by introducing feedback to the diode by off-axis self-injection locking ${ }^{1}$. However, this technique cannot be directly applied to segmented diode lasers as the segments usually are mutually incoherent.

Here, we present an off-axis self-injection locking setup of a segmented diode laser that includes two feedback arms. The purpose of the first feedback arm is to overlap the output beams from the different segments. Thereby, it is possibly to apply off-axis self-injection locking to the individual segments successfully, which is performed in the second arm. The procedure results in an overall improvement of the beam quality that can exceed the beam quality of the individual emitters. Results with a 5 segmented diode are presented.

\section{Experimental}

A schematic of the double feedback setup is shown in Fig. 1. The laser system consists of a microlens that collimates the beam along the fast axis (y-axis), a cylindrical lens that collimates the beam along the slow axis (x-axis), a diffraction grating placed in the Fourier plane with respect to the slow axis, an output coupler and a mirror. The principle behind the external cavity design is selective offaxis self-injection locking of the individual elements in the diode along the slow axis with the aid of spectral beam combining ${ }^{2}$.

\section{Results}

Fig. 2 shows slow axis intensity profiles of the output

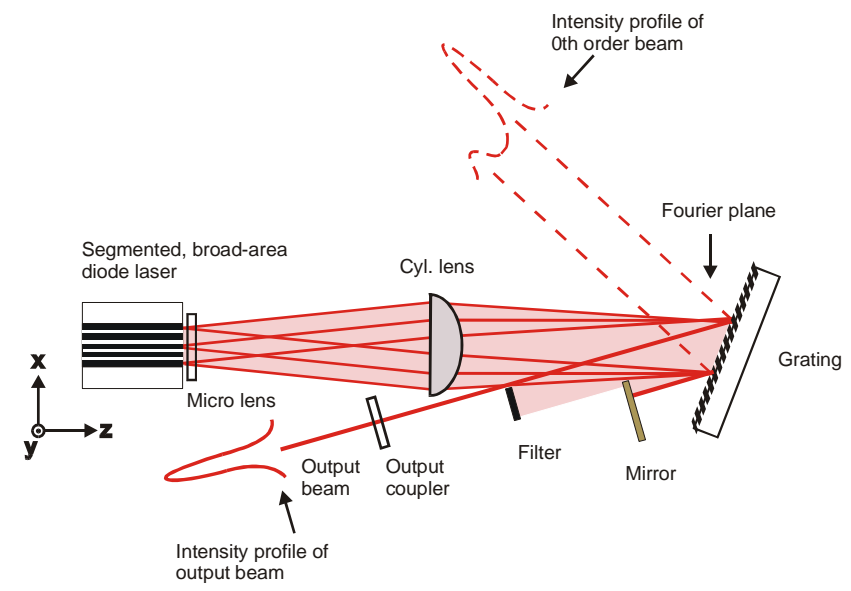
beam at single and double feedback, measured at beam waist, for a 5W, $500 \mu \mathrm{m}$ wide, 5 segmented $808 \mathrm{~nm}$ diode laser operating at 1.6 A. The output beam is focused with a cylindrical lens. Using single feedback from the output coupler, the beam quality can be improved from an $M^{2}$ value above 25 to $M^{2}=7$. Introducing the double feedback, the beam quality is improved even further to around $M^{2}=3$. In the figure, this improvement is seen as a more Gaussian-like intensity profile at double feedback. Similar results has been obtained for a drive current of 2.2 A (1.5 times the threshold current).

\section{Summary}

A new setup for improving the beam quality of a segmented broadstripe diode laser is presented. The beam quality of a 5 segmented diode laser is improved from an $M^{2}$ value above 25 to $M^{2}=3$ at a drive current of 1.6 A using this setup.

\section{References}

Fig. 1 Schematic of the diode laser system

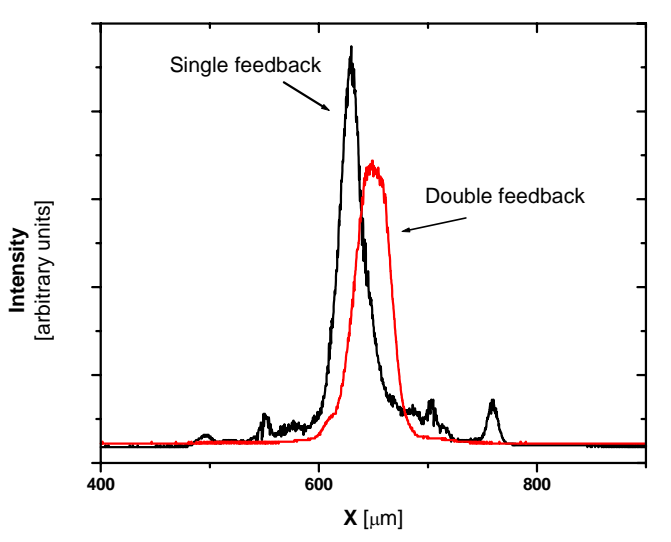

Fig. 2 Intensity profiles of focused output beams at single and double feedback. The curve heights in the two cases are not comparable.

1. B. Thestrup, M. Chi, B. Sass, P.M. Petersen, Appl. Phys. Lett. 82 (2003) 680-682

2. V. Daneu, A. Sanchez, T.Y. Fan, H.K. Choi, G.W. Turner, C.C. Cook, Opt. Lett. 25 (2000) 405-407 